\title{
ARBUTIN IN SERRATULA QUINQUEFOLIA M.B. (ASTERACEAE)
}

\author{
GERARD NOWAK ${ }^{1}$, JOANNA NAWROT ${ }^{1}$, KAROL LATOWSKI $^{2}$ \\ ${ }^{1}$ Department of Medicinal and Cosmetic Natural Products, \\ Poznan University of Medical Sciences \\ Mazowiecka 33, 60-623 Poznań, Poland \\ e-mail: gnowak@ump.edu.pl \\ 2 Department of Plant Taxonomy, Adam Mickiewicz University \\ Umultowska 89, 61-614 Poznań, Poland
}

(Received: January 12, 2009. Accepted: May 7, 2009)

\begin{abstract}
Genus Serratula is known for the presence of steroid compounds which belong to the group of ecdysones. Former phytochemical works from the late sixties and early seventies indicate, in some Serratula species, the occurrence of a phenolic glycoside-arbutin. This has been confirmed in the present work through finding an $\alpha, \beta$-arbutin anomer in Serratula quinquefolia M.B. New botanical data concerning the classification of genus Serratula suggest that the species in question should be regarded as belonging to genus Klasea (currently a section of genus Serratula). There has been an attempt to find a key to the chemical division within the taxons.
\end{abstract}

Key words: arbutin, Serratula, Klasea, Centaureinae, Asteraceae, ecdysones, chemotaxonomy.

\section{INTRODUCTION}

The systematics of Klasea Cass causes much controversy and is still a subject of discussions among botanists. This taxon is sometimes considered an autonomous genus, or a section of genus Serratula L., and it used to be regarded as Rhaponticum subgenus. At present, the distinctness of Klasea on the level of genus is being emphasized, through most of the current floristic works still tend to follow the traditional classification with the Klasea section within Serratula. The Klasea species occur in the range of places reaching from Southern and Eastern Europe through Northern Africa to western Asia, with special mention of the mountains in Central Asia (Martins 2006). They belong to subtribe Centaureinae (Asteraceae) and they are sister species to the Rhaponticum group (Martins and Hellwig 2005), where mainly sesquiterpene lactones and ecdysones have been found (Nowak 1992; Cis et al. 2006).

On the basis of modern botanical analyses, Serratula quinquefolia is ascribed to genus Klasea (Martins 2005). This species occurs in Armenia, Azerbaijan, Greece, Iran, Turkey and Russia. It is identified in accordance with the morphological description in Flora SSSR (Borisova1963) and Flora of European part of the former USSR (Tsherepanov1994).

This plant is cultivated in the Garden of Department of Medical and Cosmetic Natural Products, Poznan Medical University of Sciences (Poland). From the dry herb of this species, arbutin (hydroquinone - glucopyranoside) was isolated. By spectral methods: ${ }^{1} \mathrm{H}$ NMR and ${ }^{13} \mathrm{C}$ NMR it was established as a mixture of $\alpha$ and $\beta$ epimers.

Arbutin is a well known compound occurring in such herbal medicines as Arctostaphylos uva-ursi and Vaccinium vitis-idaea (Ericaceae), Majorana hortensis and Origanum vulgare (Lamiaceae) as well as in Bergenia crassifolia (Saxifragaceae), Pyrus communis (Rosaceae) and $\mathrm{Vi}$ burnum opulus (Caprifoliaceae).

Herbal medicines which include arbutin in the appropriate concentration display a disinfecting activity on urinary tracts, thanks to its hydrolysis, which leads to the formation of active hydroquinone (Weiss and Fintelmann 2000). This compound is also responsible for inhibiting the biosynthesis of melatonin, and applied in the treatment of hyperpigmentation (Maeda and Fakuda 1996). Arbutin has been also found in some species of genus Serratula $-S$. erucifolia, S. gmelini, S. radiata (Yatsyuk et al. 1968) and S. sogdiana (Zatsny 1973). Each of these were classified as belonging to genus Klasea in a recent taxonomic study (Martins 2006).

Ecdysones constitute the second group of the compounds to be found in the species of genus Serratula $-S$. algida (Novoselskaya et al. 1981), S. chinensis (Chen and Wei 1989), S. centauroides, S. coronata (Gorovits et al. 1974), S. inermis (Yatsyuk and Segel 1970), S. komarovii (Vorob'eva et al. 2004), S. lyratifolia (Ganiev 1980), S. procumbens (Novoselskya et al. 1981), S. quinquefolia (Goro- 
TABLE 1. Ecdysones and arbutin in Serratula genus.

\begin{tabular}{|c|c|c|c|}
\hline Species & Synonyms & Ecd. & Arb. \\
\hline Serratula algida Iljin & - & +1 & \\
\hline S. centauroides $\mathrm{L}$. & S. pectinata Turcz. ex Herd. = Klasea centauroides (L.) Cass. ex Kitagawa & $+^{2}$ & \\
\hline S. chinensis S. Moore & $\begin{array}{l}\text { Klasea chinensis }(\text { S. Moore) Kitagawa = Rhaponticum chinense }(\text { S. Moore }) \\
\text { L. Martins = Centaurea missionis H. Lév. }\end{array}$ & $++^{3}$ & \\
\hline S. coronata $\mathrm{L}$. & S. wolffii Andrae $=S$. coronata L. var. manshurica Kitagawa $=S$. manshurica & +4.19 & \\
\hline S. erucifolia (L.) Boriss & $\begin{array}{l}\text { S. xeranthemoides M. Bieb. = Xeranthemum erucifolium } \mathrm{L} .=\text { Klasea erucifolia }(\mathrm{L} .) \\
\text { Gaertner et Wagenitz }\end{array}$ & $+^{5}$ & $++^{6}$ \\
\hline S. gmelinii Tausch & S. isophylla Claus $=$ Klasea gmelinii $($ Tausch $)$ Holub & & $++^{7}$ \\
\hline S. inermis Gilib. & $\begin{array}{l}\text { S. tinctoria ssp. inermis var. angustiloba M. Pop. } \\
\text { S. tinctoria auct. fl. ross. non L. }\end{array}$ & $+^{8}$ & \\
\hline S. komarovii Iljin & Klasea komarovii (Iljin) Kitagawa = K. centauroides ssp. komarovii (Iljin) L. Martins & +9 & \\
\hline S. lyratifolia Schrenk & Klasea lyratifolia (Schrenk) L. Martins & +10 & \\
\hline S. procumbens Regel & S. flexicaulis Rupr. $=$ S. depressa Regel. et Scmalh.= Klasea procumbens $($ Regel) Holub & $++^{11}$ & \\
\hline S. quinquefolia M. Bieb. ex Wild & Klasea quiquefolia (M. Bieb.) Cass.= Klasea quinquefolia (Wild.) Greuter et Wagenitz & $+{ }^{13}$ & $++^{14}$ \\
\hline S. radiata Bunge & $\begin{array}{l}\text { S. bracteifolia (Iljin ex Grossh.) Stank.= S. radiata } \text { ssp. bracteifolia } \\
\text { Iljin ex Grossh.= Klasea radiata (Waldst. \& Kit.) A. Löve \& D. Löve }\end{array}$ & & +12 \\
\hline S. sogdiana Bunge & Klasea sogdiana (Bunge) & $++^{15}$ & +16 \\
\hline S. strangulata Iljin & Klasea strangulata (Iljin) Kitagawa & +17 & \\
\hline S. tinctoria L. & ? S. inermis & $++^{18}$ & \\
\hline
\end{tabular}

Ecd. $=$ ecdysones

Arb. = arbutin

${ }^{1,11}$ Novoselskaya et al. (1981); ${ }^{2,13}$ Gorovits et al. (1974); ${ }^{3,4}$ Chen \& Wei (1989); ${ }^{5}$ Kolodova et al. (1979); ${ }^{6,7}, 12$ Yatsyuk et al. (1968); ${ }^{8}$ Yatsyuk \& Segel (1970); ${ }^{9}$ Vorob'eva et al. (2004); ${ }^{10}$ Ganiev (1980); ${ }^{14}$ Own study; ${ }^{15}$ Zatsny et al. (1971); ${ }^{16}$ Zatsny et al. (1973); ${ }^{17}$ Dai et al. (2002); ${ }^{18}$ Bathori et al. (1986);

${ }^{19}$ Akhmed et al. (1990).

vits et al. 1974), S. sogdiana (Zatsny et al. 1971), S. strangulata (Dai et al. 2002), S. tinctoria (Bathori et al. 1986), S. wolffii (Akhmed et al. 1990) and S. xeranthemoides (Kholodova et al. 1979). Ecdysones are steroid structures with wide pharmacological properties, such as strengthening of the organism as well as decreasing the level of cholesterol (Dinan 2001). Table 1 presents those species of Serratula, in which ecdysones and arbutin have been found so far.

The aim of this work was to isolate and identify the dominant compound in Serratula quinquefolia and to present the occurrence of arbutin and ecdysones in the Serratula genus in the chemotaxonomic aspect.

\section{MATERIAL AND METHODS}

\section{Plant material}

The Serratula quinquefolia were cultivated in the Garden of Department of Medicinal and Cosmetic Natural Products of the University of Medicinal Sciences in Poznan (Poland). Aerial parts of the plant were collected in August 2007 from plants at the flowering stage. A voucher specimen (No.162/89) has been deposited at the above-mentioned garden.

\section{Extraction, isolation and identification}

Dried aerial parts of Serratula quinquefolia (250 g) were cut into small pieces and exhaustively extracted with methanol at room temperature. The extract was concentrated under reduced pressure providing a residue $(15.5 \mathrm{~g})$, which was chromatographed on a silica gel (Merck, Art 7733) column. The column eluted with methylene chloride - methanol mixture $(8: 1)$ yielded the substance $\mathrm{A}(857 \mathrm{mg})$ in the form of long white needles, m.p. $200.5^{\circ} \mathrm{C}\left(199.5^{\circ} \mathrm{C}\right.$ cited by Rolando and Gonzales 2005). Relevant fractions containing the compound A were easily detectable on silica gel TLC plates (Merck, Art. 5553, methylene chloride - methanol 6:1, $\mathrm{R}_{\mathrm{f}}=$ 0.14 ) after spraying with anisaldehyde reagent followed by heating in the temperature of $105^{\circ} \mathrm{C}$ for 3 minutes.

The structure of the isolated compound was identified on the basis of spectral methods: ${ }^{1} \mathrm{H}$ NMR, ${ }^{13} \mathrm{C}$ NMR, ${ }^{1} \mathrm{H}$ NMR $-{ }^{13} \mathrm{C}$ NMR cosy (Varian, $600 \mathrm{MHz}$, in $\mathrm{CD}_{3} \mathrm{OD}$ ).

\section{RESULTS}

Our chemical study of methanolic extract from aerial parts of Serratula quinquefolia $250 \mathrm{~g}$ ) led to the isolation of $\alpha, \beta$-arbutin anomer (857 mg) (Fig. 1). 


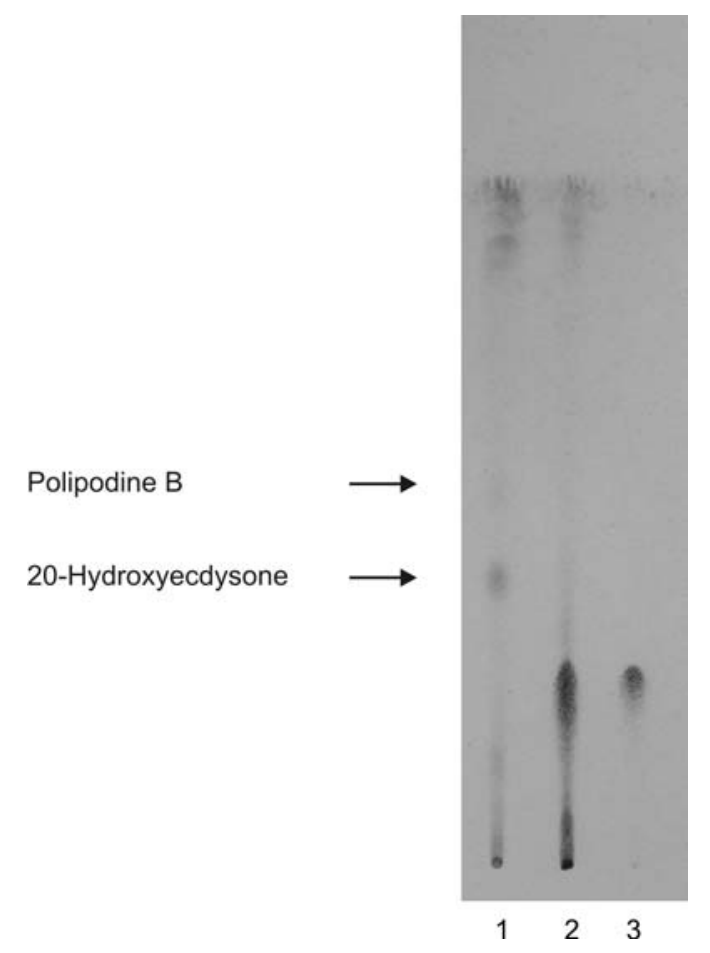

Fig. 1 Chromatogram of methanolic extracts from herbs of Serratula wolffii, S. quinquefolia and arbutin.

Methanolic extracts of: 1 - Serratula wolffii; 2 - S. quinquefolia; $3-\alpha, \beta$ arbutin. Adsorbent: silica gel. Mobile phase: methylene chloride - methanol 6:1 (V/V). Reagent: anisaldehyde.

Its molecular formula was established on the basis of spectral methods. A comparison of the ${ }^{1} \mathrm{H}$ NMR spectral data with those in literature (Rolando and Gonzales 2005) showed the presence of additional signal at the H-1'(doublet, $J_{1}, 2,=2.2 \mathrm{~Hz}$ ) what indicates the epimer $\alpha$ and the higher value of coupling constants $\left(J_{1},,{ }_{2},=7.2 \mathrm{~Hz}\right)$ of the doublet (chemical shift $4.72 \mathrm{ppm}$ ) indicates epimer $\beta$. The ${ }^{1} \mathrm{H}$ NMR spectra analyse demonstrated (Table 2 ) that the isolated compound $\mathrm{A}$ is arbutin's $\alpha, \beta$ anomer in the ratio 1:1.9 (Fig. 2).

\section{CONCLUSION}

The inclusion of the taxon in question in three different genera in literature (see Table 1), confirms major difficul-

TABLE 2. Proton NMR spectral data of substance A (600 MHz, $\left.\mathrm{CD}_{3} \mathrm{OH}\right)$ and $\beta$-D-arbutin $\left(500 \mathrm{MHz}, \mathrm{D}_{2} \mathrm{O}\right)$.

\begin{tabular}{|c|c|c|}
\hline Protons & $\begin{array}{c}\text { Substance A } \\
{ }^{1} \mathrm{H} \delta(J)\end{array}$ & $\begin{array}{c}\beta \text {-D-arbutin }{ }^{1} \\
{ }^{1} \mathrm{H} \delta(J)\end{array}$ \\
\hline $\mathrm{H}-1, \mathrm{H}-2$ & 6.98 & $6.94 d$ \\
\hline $\mathrm{H}-3, \mathrm{H}-5$ & 6.84 & $6.76 d$ \\
\hline$H-1$ ' $\beta$ & $4.72 d J_{1^{\prime}, 2},=7.7$ & $4.86 d J_{1^{\prime}, 2},=7.8$ \\
\hline $\mathrm{H}-1{ }^{\prime}{ }^{\prime} \alpha$ & $4.72 d J_{1,,{ }^{\prime},}=2.2$ & \\
\hline H-6’ A & 3.86 & $3.81 d$ \\
\hline H-6’ B & 3.71 & $3.65 d d$ \\
\hline H-2'-H-5' & $3.53-3.25 \mathrm{~m}$ & $3.54-3.38 \mathrm{~m}$ \\
\hline
\end{tabular}

${ }^{1}$ Rolando and Gonzalez (2005)

$d$ - doublet

$m$ - multiplet<smiles>C[C@@H]1O[C@H](Oc2ccc(O)cc2)C(O)C(O)C1O</smiles>

$\beta$-epimer<smiles>CC1O[C@H](Oc2ccc(O)cc2)C(O)C(O)C1O</smiles>

$\alpha$-epimer
Fig. 2. Chemical structure of arbutin - hydroquinone- $\alpha, \beta-\mathrm{D}$-glucopyranoside.

ties in establishing the correct systematics of genus Serratula

If we assume the botanical division into the two separate genera: Klasea and Serratula, we can make the following remarks.

The phytochemical analyses conducted hitherto indicate that it is impossible to make an adequate division among the species of Serratula and those seemingly belonging to Klasea. However, there is the following pattern: in Serratula arbutin has not been found so far, but in Klasea the ecdysones prevail - out of the 11 species analysed, nine contain the very compounds. Arbutin was found in five species (including the results of present work). There are species of Klasea containing ecdysones only: Klasea centauroides, $K$ chinensis, $K$. komarovii, $K$. lyratifolia, $K$. procumbens and $K$. strangulata. The following species contain both: Klasea erucifolia, $K$. quinquefolia and $K$. sogdiana.

Arbutin has been isolated from Serratula quinquefolia as a $\alpha, \beta$-glucoside. Epimer $\beta$ prevails in the amount of $65 \%$. Ecdysones were not found in Serratula quinquefolia, through the methods employed in this present work.

\section{LITERATURE CITED}

AKHAMED L., VOZIYAN P.A., KLYASHTOMAYA G.V., MILADERA K., KHOLODOVA Y.D. 1990. Serratula tinctoria L. and S. wolffii Andrae - promising sources of biologically active ecdysteroids. Ukr. Botan. Zhurn. 47: 81-83.

BATHORI M., SZENDREI K., HERKE I. 1986. Application of combined chromatographic techniques in the screening and purification of ecdysteroids. Chromatographia 21: 234-238.

BORISOVA A.G. 1963. Serratula L. In: Bobrov E.G., Tsherepanov S.K. (eds), Flora SSSR 28: 259-301. Izdatielstvo Akademii Nauk SSSR. Mockva-Leningrad.

CHEN J., WEI Y. 1989. Isolation and identification of ecdysterone in Serratula chinensis root. Zhongcaoyao. 20: 296.

CIS J., NOWAK G., KISIEL W. 2006. Antifeedant properties and chemotaxonomic implications of sesquiterpene lactones and syryngin from Rhaponticum pulchrum. Biochem. Syst. Ecol. 34: 862-867.

DAI J.Q., CAI Y.J., SHI Y.P., ZHANG Y.H., LIU Z.L., YANG L., Li Y. 2002. Antioxidant activity of ecdysteroids from Serratula strangulata. Chin. J. Chem. 20: 497-501.

DINAN L. 2001. Phytoecdysteroids: biological aspects. Phytochemistry $57:$ 325-339. 
GANIEV S.G. 1980. Amount of ecdysones in some plants of Serratula L. and Rhaponticum Ludw. Rastitielny Resursy 16: 193-198.

GOROVITS M.B., ZATSNY I.L., ABUBAKIROV N.K. 1974. Revive: ecdysones in the plant world. Rastitielny Resursy 10: 261-274.

KOLODOVA Y. D., BALTAEV U., VOLOVENKO V.O., GOROVITS M.B., ABUBAKIROV N.K. 1979. Phytoecdysones of Serratula xeranthemoides. Chem. Nat. Comp. 15: 171-174.

MARTINS L. 2006. Systematics and biogeography of Klasea (Asteraceae-Cardueae) and a synopsis of the genus. Bot. J. Linn. Soc. 152: 435-464.

MARTINS L., HELLWIG F.H. 2005. Systematic position of the genera Serratula and Klasea within Centaureinae (Cardueae, Asteraceae) inferred from ETS and ITS sequence data and new combinations in Klasea. Taxon. 54: 632-638.

MAEDA K., FAKUDA M. 1996. Arbutin: mechanism of its depigmenting action in human melanocyte culture. J. Pharmacol. Exp. Ther. 276: 765-769.

NOVOSELSKAYA I.L., GOROVITS M.B., ABUBAKIROV N.K. 1981. Phytoecdysteroids from Serratula coronata. Khimiya Prirodnykh Soedinenii. 668-669.

NOWAK G. 1992. A chemotaxonomic study of sesquiterpene lactones from subtribe Centaureinae of the Compositae. Phytochemistry 31: 2363-2368.
ROLANDO A.F., GONZALEZ M.D. 2005. Chemical study of water extract of Argentine commercial origanum. J. Argent. Chem. Soc. 93: 5 4-6.

TSHEREPANOV S.K. 1995. Serratula L. In: Vascular plants of Russia and adjacent states (the former USSR). Cambridge Univ. Press, p. 99. Cambridge, New York, Melbourne.

VOROB'EVA A., RYBIN V., ZAREMBO E., BOLTENKOV E, VERBITSKII G. 2004. Phytoecdysteroids from Serratula komarovii. Chem. Nat. Comp. 40: 492-495.

WEISS R.F., FINTELMANN V. 2000. Herbal Medicine. Thieme, Stuttgart-New York, p. 223.

YATSYUK Y.K., LYASHENKO S.S., BATYUK V.S. 1968. The content of arbutin in some species of the genus Serratula. Khimiya Prirodnykh Soedinenii. 4: 54.

YATSYUK Y.K., SEGEL G.M. 1970. The separation of ecdysterone. Khimiya Prirodnykh Soedinenii. 6: 281.

ZATSNY I.L., GOROVITS M.B., ABUBAKIROV N.K. 1971. Ecdysterone from Serratula sogdiana. Khimiya Prirodnykh Soedinenii. 6: 840-841.

ZATSNY I.L., GOROVITS M.B., ABUBAKIROV N.K. 1973. Arbutin from Serratula sogdiana. Khimiya Prirodnykh Soedinenii. 3: 437-438. 